\title{
O transporte coletivo como 'grande problema sem resolução': O não associativismo e a contestação pública de mazelas
}

\section{Ailton Gualande Junior}

Universidade Federal do Rio de Janeiro, Rio de Janeiro, RJ, Brasil

\begin{abstract}
Este artigo objetiva discutir os limites conceituais das noções de problema público e arena pública. Fundamenta-se nos resultados de uma pesquisa sobre críticas de usuários ao transporte coletivo da cidade do Rio de Janeiro. Nesse contexto, o não associativismo surge como modalidade de ação coletiva e de formação de públicos abstratos e dispersos. Ao mesmo tempo, os transtornos relacionados ao serviço de mobilidade urbana carioca se tornam extremamente complexos e rotinizados no cotidiano, conformando um grande problema público, compreendido pelos atores como um fenômeno sem solução ou que não se resolve.
\end{abstract}

Palavras-chave: arenas públicas, crítica, não associativismo, transporte coletivo, Rio de Janeiro
Public Transportation as a 'Major Problem with no Resolution': Non-associativism and Public Contestation of Recklessness discusses the conceptual limits of the notions of public problem and public arena. It is based on the results of a research on the criticism from users of public transportation in the city of Rio de Janeiro. In this context, non-associativism emerges as a form of collective action and the formation of abstract and dispersed publics. At the same time, the disorders related to the urban mobility service in Rio de Janeiro become extremely complex and routine in everyday life, forming a major public problem understood by the actors as an unsolvable phenomenon or one that does not have a solution.

Keywords: public arenas, critic, non-associativism, collective transportation, Rio de Janeiro

$\mathbf{0}$ transporte coletivo de passageiros caracteriza-se como um serviço público intensamente questionado pelo público por ele atendido ${ }^{1}$. A superlotação da frota e os longos períodos de espera para embarque são algumas das principais queixas. As contestações a essa realidade estão presentes na dinâmica do transporte há várias décadas (MOISÉS e ALLIER, 1978), principalmente em grandes centros urbanos como o Rio de Janeiro. Os antigos "quebra-quebras" (Ibid.) de ônibus, trens, estações e terminais equivalem atualmente às depredações e aos incêndios, demonstrando o extravasamento abrupto do sentimento de indignação de quem depende do serviço.

Em uma dimensão menos violenta, encontra-se a exposição de denúncias veiculadas em notícias e reportagens na mídia impressa e televisiva. Diante de câmeras e microfones, as reclamações se repetem cotidianamente, apontando para a percepção, por parte dos passageiros, de que enfrentam um problema sem aparente resolução, visto que as críticas mobilizadas por eles se repetem ao longo do tempo e se referem às mesmas mazelas, sem, contudo, serem sanadas. Isso contribui para conformar um cenário em que as deficiências na prestação do serviço pareçam não ter solução, justamente por se perpetuarem por décadas. No contexto carioca, relatos como os reproduzidos a seguir se multiplicam nos meios de comunicação: 
Olá. Eu gostaria de reclamar das situações dos ônibus no Rio de Janeiro: estão sujos, com baratas muitas vezes, quebrados, com muitos problemas. E muitos, muitos ainda circulam sem ar-condicionado. E aí pedem para aumentar a passagem. Como podem ter essa cara de pau tão grande? Aumentaram tanto nesses últimos anos e não fizeram melhorias em nosso favor. Agora querem que acreditemos que isso nos ajudará? Nem pensar (EXTRA, 12/06/2017, p. 4 [Depoimento de Débora])

Saio de casa três horas e meia antes do horário do trabalho, mas mesmo assim tem dia em que chego atrasada por causa dos problemas com os ônibus. Para piorar, o Bilhete único acaba estourando o prazo, e tenho que pagar a segunda condução do meu bolso. Para ir embora, já entrei na fila às17h, para só sair depois das 19h, e o despachante só dizia para ligar para a empresa. A gente paga imposto, paga passagem cara... E é tudo péssimo. Esse pessoal tinha que tomar vergonha na cara e devolver nosso dinheiro (OTAVIO et al., 15/11/2017, p. 7 [Depoimento de Adriana, diarista]).

Os trechos de falas, publicados pelo jornal Extra², representam reclamações de usuários a respeito do serviço de transporte coletivo da cidade do Rio de Janeiro operado por ônibus convencionais e do sistema de transporte rápido por ônibus ou BRT (bus rapid transit, em inglês). Eles são exemplos de contestação contra aquilo considerado problemático ou injusto na experiência citadina de circulação em uma grande metrópole.

Neste artigo, parto do entendimento de que a crítica, formulada como algo problemático e injusto, é um dispositivo integrante da formação de públicos abstratos e dispersos (TARDE, 2005[1901]), na medida em que permite a convergência de pensamentos comuns compartilhados por um grande número de pessoas, nesse caso, os passageiros. Nessa chave analítica, o público é uma multidão dispersa, em que a influência recíproca dos seres se caracteriza como uma ação a distância. Tal definição se coloca a partir da concepção de Gabriel Tarde sobre a opinião e os modos de propagação e contágio, possíveis por meio da figura do publicista (jornalista) como alguém responsável por disseminar ao maior número possível de pessoas as opiniões distantes (Ibid.).

Lida no contexto do século XXI, essa premissa é expandida para outras esferas da vida social, como, mais atualmente, a das redes sociais, responsáveis em grande medida por proporcionar a interação entre os atores. Antes mesmo delas, porém, a televisão - em especial os telejornais e o rádio desempenham o papel de conectar telespectadores distantes em torno de uma questão comum. Para Tarde (Ibid., p. 5), “o público se forma como uma coletividade puramente espiritual, como uma disseminação de indivíduos fisicamente separados e cuja coesão é inteiramente mental", configurando-se como um ajuntamento racional capaz de agir reflexivamente.

Partindo dessa ideia, e ajustando-a ao objeto em questão, busco analisar como o transporte impulsiona a constituição de um tipo de público (Ibid.) específico, conformador de um desenho peculiar da noção de problema público (GUSFIELD, 1963, 1981; CEFAÏ, 1996, 2014) urbano no Rio de Janeiro. Semelhante questionamento norteará as discussões a respeito da formação e do eclipsamento de arenas públicas (CEFAÏ, 2011, 2012[2002]) não associativas dedicadas ao tema. 
Busco demonstrar como a crítica de usuários ao transporte se manifesta de maneira dispersa, propiciando o surgimento de públicos, também dispersos, em que a modalidade de ação contestatória ocorre por meio do não associativismo. Proponho uma interpretação alternativa das definições conceituais tradicionais de problemas públicos, em especial quando estes parecem não oferecer horizonte de resolução, como no caso do objeto analisado neste artigo.

A análise se fundamenta nos resultados de uma pesquisa (GUALANDE JUNIOR, 2019) em que busquei examinar críticas de usuários do transporte coletivo realizado por ônibus e do BRT, veiculadas em uma seção de reclamações e eventualmente em matérias do jornal local Extra. A análise das contestações presentes no material jornalístico abarcou o período entre 2008 e $2017^{3}$. Essa escolha está ajustada ao ritmo da política carioca: 2008 marcou o fim do segundo mandato do prefeito Cesar Maia (Democratas), ocasião em que houve a primeira tentativa de realizar uma licitação das linhas de ônibus na cidade. O caso tornou-se uma controvérsia entre empresas permissionárias e a Prefeitura do Rio, pondo o transporte em evidência na agenda pública e consequentemente gerando debates sobre as deficiências constitutivas de seu funcionamento.

No ano seguinte, Maia foi substituído por Eduardo Paes (PMDB), que realizou uma série de reformulações no sistema de transporte coletivo urbano do Rio de Janeiro, principalmente em relação aos ônibus, por meio de uma licitação para concessão do serviço e da inauguração do primeiro corredor expresso do BRT, em 2012. Essas alterações estavam, em grande medida, conectadas aos projetos de cidade sede da Copa do Mundo de 2014 e dos Jogos Olímpicos de 2016. A mobilidade urbana se impunha como desafio diante da necessidade de locomoção de número expressivo de turistas no período dos eventos.

Por fim, em 2017, primeiro ano de mandato de Marcelo Crivella (Republicanos, reativou-se os embates entre poder público e concessionárias, principalmente em relação às disputas sobre as definições justas do preço das tarifas. Outro ponto sensível de controvérsia referia-se à implementação de refrigeração em toda a frota operante, tema constantemente lembrado pelos usuários, moradores de uma cidade com verões intensos.

Esse fio temporal permite apreender os modos como se delinearam tais reformulações e, mais especificamente, o sentido conferido a elas por parte dos usuários, membros de entidades interessadas e agentes estatais. O jornal Extra conta com uma seção denominada "Carta Branca/Comunidade", em que leitores enviam críticas, sugestões e reclamações a respeito da má prestação de serviços públicos, como saúde, iluminação pública, coleta de lixo, manutenção de calçamento e redes de água e esgoto, além de transporte coletivo. Na pesquisa, mapeei todas as falas veiculadas nessa seção e em reportagens do jornal cujo tema principal se remetesse a meu objeto. Assim, pude compreender como o assunto se manteve na agenda pública, tendo um dos periódicos de maior circulação no Rio como campo de coleta de dados. 
Foram classificadas 432 reclamações de usuários para análise, divididas ano a ano ${ }^{4}$. O material foi examinado por meio da distinção entre forma e conteúdo na maneira como as críticas foram formuladas e publicizadas. Em relação à forma, procurei isolar tópicos constantemente instrumentalizados, imbuídos de generalidade construída por procedimentos internos mais ou menos coesos, compreendidos em torno de uma estabilidade temporal, da extensão de sua validade e da objetividade de seu conteúdo (THÉVENOT, 1986). Os principais exemplos de forma são as categorias de "desabafo", "desrespeito", “descaso" e "sofrimento", externadas pelos usuários. Quanto ao conteúdo, elenquei itens referentes aos problemas em si (materiais, concretos) lembrados pelos reclamantes, como a superlotação dos ônibus, o tempo elevado de espera para embarque, o mau estado de conservação da frota etc. Essa distinção permitiu compreender os repertórios mobilizados por usuários no movimento de contestação às mazelas na prestação do serviço.

\section{A composição de uma ordem problemática}

As críticas publicizadas na opinião pública permitem dimensionar duas escalas de discussão sobre o transporte coletivo carioca. De um lado, encontra-se a decomposição desse serviço em diversos fenômenos qualificados como adversos, configurando críticas mais objetivas (WERNECK e LORETTI, 2018): acidentes de ônibus com vítimas fatais; alterações de linhas e itinerários; superlotação dos veículos; sucateamento da frota; o preço cobrado pela tarifa; a não refrigeração de $100 \%$ dos ônibus; elevado tempo de espera em pontos e terminais; desrespeito de motoristas, principalmente com idosos, deficientes e estudantes, ou seja, grupos não pagantes; escândalos de corrupção no setor; entre outros. Todos esses fenômenos ocorreram a partir da enunciação de ocorrências e/ou "casos" (BOLTANSKI, 2000[1990]; CLAVERIE, 1998) particulares.

De outro lado, a junção dessas peças forma um grande problema, um mosaico, em que as críticas acumuladas constroem uma crítica geral e formulada de maneira vaga (WERNECK e LORETTI, 2018) ao se referirem ao problema-transporte-coletivo como um todo. Esse dimensionamento atinge no caso observado um grau extremo de generalização, contribuindo para que demandas específicas dos usuários sejam eclipsadas pela forma conferida ao grande problema. Como em um mosaico, visto a certa distância, as peças componentes dele acabam despercebidas em função do desenho final.

Apresentarei a seguir a operacionalização dessa última dimensão e o modo como ela contribuiu para a construção, ao longo de uma década, da mobilidade urbana de massa como um grande problema público, fenômeno enxergado como irresolvível, persistindo ao longo do tempo. 
Síntese

As contestações englobantes de um modelo vago/genérico (WERNECK e LORETTI, 2018 estão presentes de maneira determinante no transporte coletivo carioca. Os transtornos elencados como exemplos na seção anterior foram os mais lembrados pelos usuários entre 2008 e 2017, tanto nas falas veiculadas pelo Extra como na estatística oficial elaborada pela Secretaria Municipal de Transportes (SMTR). Juntos, constituem uma síntese sobre as deficiências presentes no transporte, contribuindo para a percepção de uma espécie de "grande problema que não se resolve". A ideia de sistema confere sentido a um fenômeno complexo que tende a se reproduzir em um processo de ordenamento de ações e rotinas sem conferir a devida atenção aos atores. Assim como na imagem do mosaico, a elaboração de críticas em relação a uma síntese de problemas caracterizadores do transporte acaba por eclipsar as peças integrantes, na medida em que se apresenta como a forma do desenho visto a distância como um todo homogêneo.

Nesse sentido, as insatisfações são publicizadas em um esquema rotinizador de extrema generalização e repetição. Vejamos o caso do BRT:

Figura 1: Reportagem sobre problemas na oferta do serviço de BRT

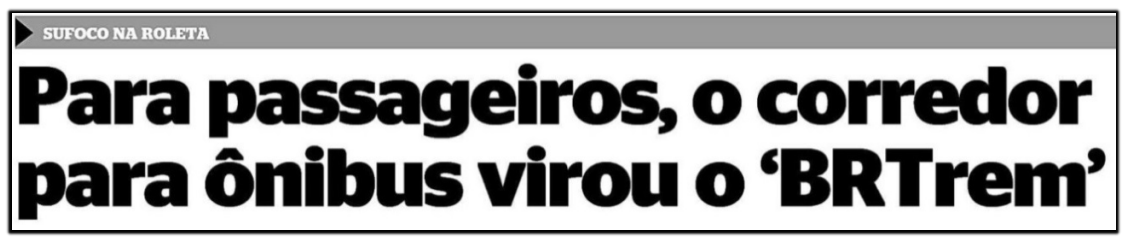

Fonte: Extra (01/07/12).

A chegada à estação Santa Cruz, às 6h, tem início com a disputa pelo melhor lugar. Todas as portas que dão acesso ao ônibus ficam cercadas por uma multidão, que se espreme para entrar com maior rapidez no veículo. Correria, empurrões e gritos, já conhecidos por usuários do trem e do metrô, se repetem no sistema inaugurado com a proposta de ser um sistema rápido e confortável (RAMIRO, 01/07/12, p. 15) 5 .

Fica muito complicado para chegar ao trabalho viajando no ônibus nestas condições. A estação Mato Alto é a mais cheia de todas. Chega ser insuportável de tão cheia que fica. Hoje (anteontem), o ônibus está circulando sem ar-condicionado. Mas quando o ônibus está muito cheio e a refrigeração funciona, também não dá vazão. Se estivesse fazendo um dia de calor de 40 C, tinha morrido todo mundo (BRAGA, 22/03/2013, p. 4 [Depoimento de Márcia Regina, encarregada]).

É muito triste precisar usar o BRT. Está sempre lotado, mal conseguimos respirar. Os horários são irregulares. Troquei o trem pelo BRT, mas estou vendo que são dois transportes abandonados. Pagamos nossos impostos em dia e precisamos chegar descansados em casa após um dia de trabalho cansativo (EXTRA,10/06/2015, p. 6 [Depoimento de Lúcia Souza, do Méier]). 
O primeiro corredor expresso do BRT, o TransOeste, foi inaugurado em 6 de junho de 2012, interligando os bairros de Santa Cruz e Barra da Tijuca. A reportagem anterior e as falas dos usuários apontam para o fato de, desde o início, o sistema ter sido alvo de críticas. A superlotação dos veículos, principalmente nos horários de pico, e as grandes filas para embarcar foram os primeiros problemas apontados como fonte de incômodo, o que levou à comparação com outro modal do transporte carioca, o trem. E o ponto fundamental aqui é que o sistema ferroviário que atende à cidade historicamente ficou marcado pelo estigma de estar sempre sobrecarregado de passageiros e apresentar problemas técnicos constantes. Apesar de ter passado por mudanças, como a renovação total das composições, com a totalidade dos vagões refrigerados essa imagem caótica permaneceu no imaginário ${ }^{6}$.

Por outro lado, a redução no tempo dos deslocamentos entre os pontos inicial e final foi uma qualidade lembrada pelos usuários dos corredores exclusivos. No entanto, as inúmeras falhas na execução do projeto, como a degradação do asfalto dos corredores e o subdimensionamento da demanda, além das questões de segurança pública e dos acidentes envolvendo os veículos articulados, minaram a percepção e as consequentes qualificações positivas de boa parte dos usuários sobre o serviço prestado.

De maneira semelhante ao que ocorre com o BRT, as críticas fazem parte do cotidiano de quem utiliza o sistema de ônibus convencionais, intensamente contestado ao longo dos últimos dez anos. Por exemplo:

Figura 2: Reportagem sobre problemas na oferta do serviço de ônibus convencionais

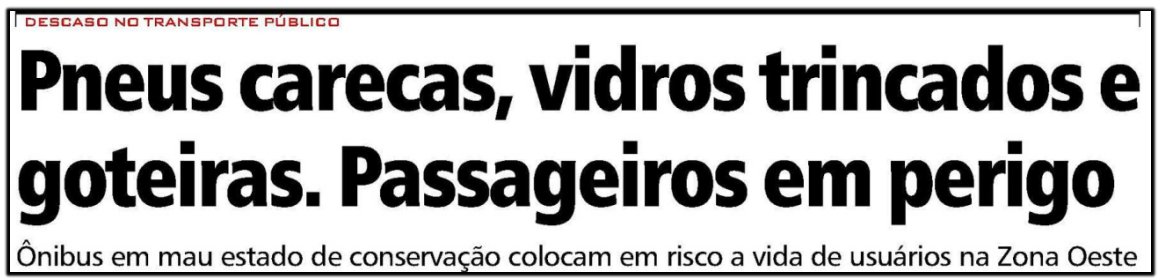
Fonte: Rohde (06/02/2009, p. 3).

\footnotetext{
Estamos precisando urgentemente de uma intervenção das autoridades na linha 388 (Santa Cruz-Coelho Neto). Os carros passam lotados, escuros e deixando os passageiros a pé. Pedimos uma providência, pois todos que necessitam dessa linha passam por muitos apuros todos os dias (EXTRA, 19/05/2010, p. 2 [Depoimento de Flavio, de Guadalupe, Zona Norte]).

Os ônibus da linha 756 e 759, da Viação Algarve, estão precisando de concorrência! Demorou mais de uma hora para passar e, quando passam, estão superlotados e não param nos pontos. À noite, vêm escuros e mal podemos enxergá-los. O pior é que já foram feitas muitas reclamações e nada foi feito (Idem, 30/11/2011, p. 2 [Depoimento de Juliana, de Paciência, Zona Oeste]).
} 
Sou morador de Bangu e não aguento mais as péssimas condições de conservação dos ônibus 383, 739 e 742, da Viação Bangu. Todos os veículos estão caindo aos pedaços, com muita sujeira e baratas. Além do desconforto, o intervalo entre um e outro é de duas horas. Já fiz diversos contatos com a Prefeitura, mas não houve melhorias (Idem, 12/04/2014, p. 2 [Depoimento de Mauro, de Bangu, Zona Oeste]).

Pego o 892 (Santa Cruz-São Benedito), e todos os ônibus dessa linha estão em péssimas condições. São bancos rasgados e vidros balançando, parece que vai desmoronar. Você paga por um serviço que não recebe e acaba tendo isso aí (RIBEIRO, 25/06/2017, p. 5 [Depoimento de Adriano, mecânico de Santa Cruz, Zona Oeste]).

Em uma primeira aproximação teórica, esse cenário de transtornos pode ser lido a partir das contribuições de John Dewey (2008[1927]). A definição de fenômenos problemáticos e as ações empregadas pelos atores envolvidos na busca pela sua resolução são as principais preocupações desse autor. Para ele, por exemplo, a própria noção de Estado deveria ser compreendida na chave de suas consequências e da realidade de seus fatos constitutivos, afastando-se do pressuposto filosófico do dever ser da instituição. O público, então, consistiria em um conjunto de ajuntamentos formados por pessoas afetadas pelas consequências oriundas de transações executadas (ou não executadas, no caso aqui explorado) pelo Estado, constituindo um corpo político de busca pelo reconhecimento dos transtornos causados e por sua respectiva erradicação.

O pressuposto dessa interpretação é: a adesão de muitos a um problema, tornando-o uma causa - coletiva - é o caminho para sua solução, ou pelo menos para se fazer algo consistente a seu respeito. É por meio da ideia de junção de forças que essa sociologia entende a ação política de grupos sociais a partir das críticas por eles formuladas. A adesão, como operação de engajamento, se torna, então, um elemento-chave e a mobilização, um dispositivo fundamental dessa política. Tais ideias encontram semelhanças em construções teóricas de outros pensadores, como Luc Boltanski, que, em A denúncia pública (2000[1990]), discute o processo de dessingularização promovido pelos atores em momentos de contestação de transtornos, e Joseph Gusfield (1981), que descreve a ascensão de um problema público como fenômeno construído de forma generalizante pelos grupos nele envolvidos.

Os resultados de minha pesquisa, no entanto, apontam para a possibilidade de relativização dos argumentos contidos nesses modelos, ampliando o escopo de suas propostas. Do ponto de vista dos usuários, o associativismo característico de análises inspiradas em Dewey não se coloca como modo habitual de ação. O elemento marcante desse público é a dispersão das contestações relacionadas à prestação do serviço realizado por ônibus, feitas principalmente por meio da publicização de críticas. Foi possível observar, então, que se constitui nesse caso uma modalidade não associativa de ação coletiva. Ela, percebida pela análise do material empírico, aponta para uma forma de agregação conceitual que não passa pelo movimento típico de associação em arenas 
públicas, por exemplo. A crítica circula de maneira abstrata, contribuindo para o surgimento de públicos conectados a distância e de forma dispersa.

Essa constatação nos permite realizar um diálogo com a proposta de Tarde (2005[1901]) sobre a definição de público como um ajuntamento articulado por meio da opinião pública ${ }^{7}$, seja ela difundida pelo jornal, pelas redes sociais, como o Facebook, ou na conversação ${ }^{8}$ (Ibid.) desenvolvida nos pontos de embarque e desembarque, nos terminais e nas estações. Assim, essa dispersão da crítica desagua na definição das características constitutivas do transporte coletivo - "superlotado, demorado, sucateado e caro" - , contribuindo para uma percepção negativa sobre o serviço, a essência de um grande problema público, que, no campo analisado, é visto por uma parcela dos atores como algo sem resolução aparente.

$\mathrm{Na}$ seção seguinte, apresento uma discussão teórica acerca da noção de problema público, demonstrando como me aproprio dela para pensar o objeto apresentado no artigo, ao mesmo tempo que proponho contribuições de interpretação para ela.

\section{Problema público como ferramenta analítica}

Amplamente difundidos, os termos "problema social" e "problema público" foram, durante longo tempo, utilizados indistintamente no campo das ciências sociais. Daniel Cefaï $(1996,2014)$ descreve a trajetória de diferenciação entre ambos os conceitos ocorrida a partir da década de 1960. À época, discussões a respeito do tratamento de questões sociais por meio de políticas públicas obtinham relevância no meio acadêmico e político dos EUA. Na sociologia, duas grandes teses dominavam os debates: a teoria funcionalista de Robert Merton e Robert Nisbet (1961) e a teoria de conflitos de valores, defendida por Willard Waller (1936), Richard Fuller e Richard Myers (1941a, 1941b). Merton e Nisbet (1961) estavam concentrados em analisar a desorganização social e o comportamento desviante como frutos das inadequações dos indivíduos ao sistema social concebido como padrão. Assim, o sociólogo teria condições de se portar como o agente que define as condições normais ou desejáveis de funcionamento da sociedade, elaborando diagnósticos e propostas de amenização da desordem, entendida como problema social a ser tratado. Em contrapartida, para Waller, Fuller e Myers, apenas condições objetivas não seriam capazes de designar uma realidade como problemática; os valores dos indivíduos envolvidos seriam cruciais para o processo, conformando aspectos do indesejável. Portanto, somente seria possível caracterizar um problema como social a partir do momento em que os indivíduos envolvidos o definissem assim, afastando o papel do sociólogo como ator determinante dessa condição?. 
A criação da revista acadêmica Social Problems, em 1951, proporcionou a convergência de trabalhos produzidos por pesquisadores interessados no tema. A chegada de Howard Becker ao cargo de editor do periódico, em 1961, tornou-se um ponto de inflexão no modo como as discussões a respeito dos problemas sociais vinham sendo realizadas. A consequente publicação de trabalhos de autores como Anselm Strauss (1978a, 1978b), Herbert Blumer (1971) e o próprio Becker (1966) reformulou questões da abordagem sociológica referente a fenômenos de ordem problemática. Além disso, a incorporação de análises construídas nos campos da fenomenologia de Alfred Schütz e Thomas Luckmann (1973), na etnometodologia de Harold Garfinkel (2018[1967]), na hermenêutica narrativa de Paul Ricoeur (2010[1983]) e na análise de quadros de Erving Goffman (2012[1974]) proporcionou a solidificação de um arcabouço teórico capaz de se colocar como alternativa ao relativismo presente nas análises sobre problemas sociais até então empregadas. Assim, abria-se caminho para uma distinção ainda não elaborada sobre a temática.

Detenho-me aqui no papel desempenhado por Joseph Gusfield $(1963,1981)$ nesse processo. Por ser o primeiro a propor uma definição distinta para os conceitos de problema social e público, o autor destaca-se como referencial de partida. O diálogo com suas propostas sustenta o desenvolvimento dos principais argumentos contidos nesta seção.

Gusfield (1963) debruçou-se, no âmbito de sua pesquisa de tese, sobre o campo da sociologia do comportamento coletivo e dos problemas sociais, publicando o resultado da investigação em 1963. Quase 20 anos depois, lançou uma extensa pesquisa (GUSFIELD, 1981) sobre um caso de grande repercussão nos EUA na década de 1970. Gradativamente, o ato de dirigir sob efeito de álcool (drive under influence of alcohol, DUIA) havia se tornado publicamente condenável. Determinados grupos utilizaram diferentes estratégias, como estudos científicos e estatísticas governamentais, para enfatizar o perigo incidente sobre a sociedade representado pela ação, que deveria ser erradicada. A busca pela elaboração de leis com o intuito de reprimir o ato transformou-se na grande bandeira do movimento, caracterizando-se como potente mecanismo de definição e solução de problemas públicos.

Gusfield caracterizou o fenômeno a partir da categoria drinking-driving, enfatizando a construção de uma ordem simbólica em torno do álcool, dos automóveis e dos motoristas. As análises, sob esse ponto de vista, privilegiam mais os modos como os significados são construídos e menos como o comportamento é influenciado. O estudo, assim, consolida a proposta do autor de estabelecer uma diferenciação analítica e de abordagem entre as noções de problema social e problema público, até então mobilizadas de maneira semelhante. De seu ponto de vista, a oscilação entre objetivismo e subjetivismo na definição de transtornos coletivos eclipsaria a dimensão fenomenal e política das disputas nos espaços públicos. Por isso, o objetivo de Gusfield passa a ser analisar como uma ordem simbólica é construída em torno de questões pautadas como 
problemáticas. Nessa perspectiva, o problema social caracteriza-se pela condição objetiva a partir da qual determinado grupo de pessoas confere a um tema a qualificação de problemático, e, desse modo, demandante de ações para ser solucionado. O problema é social no sentido de tocar a vida de um coletivo de indivíduos que assim o caracterizam.

Um exemplo são os dilemas enfrentados nas relações entre pais e filhos ou aqueles presentes entre casais, que à primeira vista parecem meramente privados. A principal questão concernente aos problemas sociais gira em torno da veracidade dos fatos e das formas de contorná-los por meio de ações em uma esfera doméstica e familiar, ou que não sejam capazes de se generalizar como questão pertinente para ampla problematização e debate. Do ponto de vista do modelo, então, as ocorrências não se tornariam, necessariamente, alvos de inquietações públicas. No entanto, tomando novamente a situação familiar, o ato de castigar os filhos pode se tornar um evento de preocupação generalizada.

Uma das formas de castigo, a violência física, obteve, no caso brasileiro, contornos de publicidade significativos, tornando o ato um crime tipificado em lei (BRASIL, 2014). No contexto americano, Gusfield (Ibid.) refere-se ao aborto, que, em um primeiro momento, poderia ser considerado uma questão de competência familiar ou individual e, no entanto, já na década de 1980 era tratado como um ato de extrema gravidade, sendo inclusive punido legalmente. Percebe-se com os dois exemplos o processo de transformação de questões localizadas, familiares e individuais em questionamentos públicos de condutas. Assim, os problemas sociais passam a ser compreendidos como problemas públicos, discutidos e disputados em arenas mais amplas e generalizantes, fazendo convergir grupos antagônicos.

Essa concepção rompe com o entendimento, na sociologia, de que qualquer condição problemática definida por grupos sociais - tanto casos familiares como aqueles geradores de grandes debates públicos - seriam problemas categorizados como sociais. A abordagem propõe mudanças no enfoque analítico, priorizando o processo pelo qual um assunto passa a ser considerado de interesse público, em vez de as condições que o definem como problema e as possibilidades de solução para erradicá-lo.

Assim, a institucionalidade passa a ser considerada um importante objeto de investigação: busca-se compreender quais instituições, e de que modo, são responsáveis por se dedicar ao tema, lançando-o à agenda pública. No caso do transporte coletivo carioca, a Prefeitura e a SMTR desempenham a função de responsabilidade pela condução das políticas de organização do serviço. O Rio Ônibus, por sua vez, é o sindicato representante dos consórcios responsáveis pela operação das linhas de ônibus e BRT. Entre ambos, estão situados a Câmara Municipal e sua Comissão Permanente de Transportes e Trânsito ${ }^{10}$, os movimentos sociais e coletivos que discutem a mobilidade urbana de massa e, evidentemente, a imprensa. Há ainda órgãos 
fiscalizadores, como o Ministério Público do Estado do Rio de Janeiro (MPRJ) e o Procon-RJ, frequentemente provocados a interferir na dinâmica de oferta do serviço. Por último, o Judiciário media os conflitos entre as instituições anteriores, bem como entre elas e os usuários.

A pesquisa realizada por mim sobre o transporte coletivo contribui para as discussões iniciadas por Gusfield (1963, 1981) e aprofundadas por Cefaï (1996, 2012[2002], 2011, 2014), sugerindo outras abordagens analíticas para o tema dos problemas públicos, aqui examinado em um contexto empírico diverso ao que inicialmente foi proposto (EUA). Ela permite também evidenciar as potencialidades e a maleabilidade da noção de problema público como ferramenta teórica produtiva na análise de distintos fenômenos sociais.

Nesse sentido, o primeiro ponto de contraste a ser apresentado refere-se ao fato de que, em minha pesquisa, lido com questões morais acerca do que determinados públicos consideram problemático no transporte. O reconhecimento de uma situação como dolorosa - em um regime de piedade (BOLTANSKI, 2004[1993]) e de justiça (Idem, 2000[1990]) — é um dos principais fundamentos para se conseguir pleitear uma ação de intervenção com o objetivo de sanar o sofrimento. Enquanto no drinking-driving esse aspecto está presente no apelo aos casos de mortes e feridos graves decorrentes de acidentes envolvendo motoristas consumidores de álcool, no caso do transporte público carioca o sofrimento está intimamente ligado ao convívio diário de transtornos oriundos do tempo perdido no deslocamento, do desconforto em relação ao calor no interior de muitos veículos, da superlotação dos ônibus, do assédio sexual contra mulheres e de outros pontos recorrentes nas reclamações de usuários. No transporte coletivo do Rio de Janeiro a insatisfação é amplamente reconhecida por quem utiliza os ônibus, pelas instituições responsáveis pela regulamentação e pelas prestadoras do serviço, apesar de isso não se converter necessariamente em ações efetivas de amenização das condições causadoras de desconforto e sofrimento.

Assim, a diferença entre o caso analisado por Gusfield (1981) e o meu está no fato de a má qualidade do transporte ser reconhecida por grande parte dos envolvidos diretamente em sua dinâmica, como fica evidenciado nas falas analisadas na pesquisa. Ela é reconhecida também pelos cariocas em geral, inseridos em uma realidade pública (Ibid.) em que as representações acerca das deficiências do serviço de mobilidade urbana são compartilhadas. Não se verifica, portanto, uma disputa entre grupos para tornar o fenômeno algo problemático demandante de ações para ser sanado. A questão está na pressão exercida para que a condição do transporte melhore, oferecendo dignidade aos usuários. O poder público local e as empresas concessionárias, alvos das contestações, são enxergados como os responsáveis pelo problema a ser resolvido, embora possam não reconhecer a existência desse problema.

Percebe-se, assim, uma complexa engenharia de significados e relações sociais entrecruzados nesse processo. Nesse sentido, a análise de um problema público se concentra na 
performatividade, ou seja, no processo de construção de uma ordem pública e de uma arena de ações em que o convencimento se torna elemento fundamental para os atores envolvidos na busca pela captação da atenção pública. Diferentemente dos problemas sociais, os problemas públicos são debatidos e resolvidos nas arenas públicas (Ibid.; CEFAÏ, 1996, 2011, 2012[2002]), afastandose de uma esfera doméstica, familiar, localizada ou singularizada.

\section{O modelo de ação coletiva em arenas públicas associativas}

A noção de arenas públicas remete-se a uma abstração metafísica, um meio de ordenar acontecimentos em uma dada realidade. Ela não se refere a espaços físicos propriamente ditos, mas a uma coordenação de ações em um lugar em duas dimensões: combate e encenação, uma forma social. Como sintetizado por Jussara Freire (2016), "as arenas públicas reúnem um conjunto de características definidoras, tais como a dramaturgia dos atores nos embates, a pluralidade de agentes, o conflito, as negociações, a presença de uma gramática de publicização de reivindicações, e por fim, a dispersão" (pp. 106-107).

A retomada da gênese de um problema público - as etapas formais de sua composição em dado momento - pode apresentar a seguinte formulação:

\section{Quadro 1: Etapas da constituição de problemas públicos}

\begin{tabular}{|c|l|}
\hline 1 & $\begin{array}{l}\text { Conversão de questões privadas em questões públicas; definição dos problemas; designação de } \\
\text { protagonistas; determinação de questões; destinação de discursos articulados aos poderes públicos. }\end{array}$ \\
\hline 2 & $\begin{array}{l}\text { Formação da arena pública - constituída em diferentes campos de instituições; ocorrência em diversas } \\
\text { cenas públicas; revelar de múltiplas esferas de ação pública. }\end{array}$ \\
\hline 3 & $\begin{array}{l}\text { Codificação do problema e reivindicaçães - ascensão em generalidade; invocação de princípios gerais } \\
\text { de direito ou justiça; regras de eficiência das estratégias de ação. }\end{array}$ \\
\hline 4 & $\begin{array}{l}\text { Problema público pode arrefecer pela apresentação ou pela realização de um programa de } \\
\text { ação pública e acompanhado por promessas tácitas. }\end{array}$ \\
\hline
\end{tabular}

Fonte: Organizado pelo autor a partir de Cefaï (1996, pp. 57-59).

A temporalidade e as etapas de construção de problemas públicos, além do surgimento de arenas públicas em torno deles, não ocorrem da mesma maneira em todos os casos. Do mesmo modo, as etapas apresentadas no Quadro 1 podem transcorrer em sequências distintas, ou nem mesmo chegar a se concretizar.

A linhagem de análise da noção de arena pública está intimamente ligada ao surgimento da distinção entre problema social e problema público. Em específico, ela se remete a uma contestação do modelo habermasiano de espaço público, constituído como lugar de mediação entre poder público, sociedade política, sociedade civil e meios de comunicação (CEFAÏ, 
2012[2002]). Esse modelo carrega forte conotação normativa e estática sobre o espaço público e as relações sociais estabelecidas em seu âmbito. Em contraposição a tal proposta, a noção de arena pública surge, a partir dos trabalhos de Strauss (1999[1967]) e do próprio Gusfield $(1963,1981)$, como o lugar de combates e de performances diante de uma audiência.

Essa abordagem é fortemente influenciada pelo pensamento de Dewey (2008[1927]) acerca da noção de público e do modo como ele se forma no entorno e faz parte de situações definidas como problemáticas. O processo de definição de problemas não ocorre harmoniosamente, tornando a arena pública local de disputas e intensos julgamentos morais. Cefaï (2012[2002]) retoma Dewey (2008[1927]) e Park (2007[1975]) para mostrar que a sociologia praticada por ambos no início do século XX nos EUA estava embasada em uma ciência da associação e da interação. Estava, portanto, assentada em uma concepção de sociedade coerente com a noção de público e com uma teoria pragmatista da democracia. Assim, nos moldes dos pensadores citados, uma arena pública é pensada de forma associativa, em um processo de investigação e experimentação acerca dos distúrbios da ordem social projetada pelos atores.

A capacidade de dramatização torna-se uma poderosa ferramenta de captação da atenção pública no contexto investigativo. Em uma arena, o fluxo das disputas oscila frequentemente, tornando o processo dinâmico. O sentido dramático da ação pública representa uma das formas de se organizar a experiência. $O$ recurso ancora-se na metáfora teatral, aos moldes do que propôs Goffman (2014[1959], 2012[1974]) com seus estudos sobre as interações em espaços públicos. O drama público é um ato realizado em nome de e com vistas a atingir um coletivo visível e observável. Assim, as construções performáticas adquirem sentido, como diria Gusfield (1981), a partir de determinadas crenças e significados sobre a sociedade construídos publicamente, referindo-se a eventos não experimentados isoladamente.

Assim, dificuldades e desrespeitos enfrentados diariamente por usuários do sistema de transporte coletivo urbano do Rio de Janeiro são partilhados por significativa porção da população residente nessa cidade. Essa realidade é incorporada às avaliações pessoais de outras camadas da sociedade que não utilizam o transporte público por meio do processo de publicização de experiências vivenciadas. Essa constatação está contida no imperativo de existência de um “outro generalizado" (MEAD, 1934), um espectador imparcial, atento ao desenrolar das ações e pronto a emitir juízos de valor sobre os acontecimentos ocorridos nas arenas públicas.

No campo do transporte, a última grande arena pública observada no Rio de Janeiro constituiu-se quando das manifestações de junho de $2013^{11}$. Em um momento inicial, o movimento desenvolveu-se a partir da indignação com o aumento das tarifas de ônibus nas cidades de São Paulo e Rio de Janeiro. Na ocasião, questões como a precariedade do transporte foram mobilizadas para sustentar a argumentação, por parte dos manifestantes, de que o aumento da 
tarifa era injusto e injustificável. Aquele momento foi fundamental para alçar o transporte coletivo urbano a um lugar de destaque na agenda pública das maiores cidades brasileiras. A pressão das ruas teve a capacidade de forçar agentes governamentais de diversas esferas de poder (inclusive a Presidência da República) a negociar com o Movimento Passe Livre (MPL) a revogação do aumento da tarifa em São Paulo e no Rio e a anunciar a liberação de recursos a serem aplicados em melhorias infraestruturais do sistema de mobilidade urbana em médias e grandes cidades.

A intensificação do movimento, no entanto, fez com que as demandas se pulverizassem em direção a diversos temas, como corrupção, educação e saúde (VAINER et al., 2013; CATTANI, 2014). Gradativamente, o transporte deixou de ser o fio condutor dos protestos. O ponto de inflexão nesses movimentos foi a retirada do MPL dos atos, que até então havia sido o maior articulador das ações de ocupação das ruas. O espraiamento das pautas foi acompanhado de uma radicalização da violência dos manifestantes e da dura repressão da polícia. Cerca de um mês após o início dos atos, o movimento arrefeceu. $\mathrm{O}$ caso evidencia um aspecto fundamental das arenas públicas associativas: elas surgem e se encerram de maneira incessante e dinâmica.

Uma retomada da trajetória sociológica de análise do transporte como conflito urbano demonstra que, apesar de ele afetar a vida de significativa parcela da população brasileira, os engajamentos para a formação de arenas públicas associativas nesse setor têm sido irregulares. Como mostram Hernán Mamani e Jussara Freire (2013), os casos mais abordados pelo campo sociológico se concentram nos quebra-quebras dos anos 1970 (MOISÉS e ALIER, 1978), na luta pela regulamentação do transporte informal nos anos 1990 (MAMANI, 2004) e nas reivindicações do movimento secundarista pelo passe livre (LOURENÇO, 2006). Pautas mais recorrentes, como a refrigeração da frota e a redução da superlotação dos ônibus e do tempo de espera para embarque, constam nos programas de ONGs e movimentos sociais dedicados ao tema. Contudo, é por meio da crítica formulada pelos usuários e postas em circulação em espaços públicos, redes sociais e jornais que elas têm sido tema de discussão. A crítica, assim, concretiza-se menos como movimento organizado e mais como uma arenização (problematização) dispersa, cotidiana, repetitiva.

\section{O não associativismo como forma de ação pública}

No campo analisado, o modelo associativista de ação coletiva de contestação e busca de soluções para problemas convive com outra modalidade de ação coletiva questionadora que, entretanto, não se configura como contrária ao associativismo. Os públicos do transporte coletivo carioca são dispersos e abstratos - o que não significa que sejam fracos. Essa característica permite aproximar minhas análises do pensamento de Tarde (2005[1901]) a respeito da noção de 
público, considerado por ele um agregado distinto da multidão, uma congregação fisicamente interligada, em contato direto. Parto da ideia geral desse autor para pensar como usuários do transporte se conectam sem necessariamente estarem próximos espacialmente. Esses atores configuram, assim, formas não associativas de ação. Se a dispersão das críticas e de sua recorrência, por um lado, podem colaborar para sua banalização como grande problema, por outro, podem levar à arenização desse mesmo grande problema em suas partes, afastando-se do modelo clássico de mobilização coletiva.

O fato de o transporte ser desde sempre definido como público e coletivo permite pensá-lo como uma experiência dos públicos e, portanto, passível de ser frequentemente debatida nas agendas públicas, principalmente de médias e grandes cidades, contextos em que se coloca como problema crônico de mobilidade urbana. Nesse campo, as arenas públicas não se constituem necessariamente a partir de associações formalmente instituídas ou de movimentos sociais consolidados. Demonstrarei a seguir os contrastes entre escalas de atuação de diferentes atores.

Em um nível institucional, encontram-se estruturadas a Prefeitura e a SMTR. A elas cabem a regulamentação e a fiscalização da oferta do serviço. Outro canal de encaminhamentos, previsto tanto no Estatuto da Cidade (lei $\mathrm{n}^{\mathrm{o}}$ 10.257/2001) quanto na Política Nacional de Mobilidade Urbana (lei no 12.587/2012) são os Conselhos Municipais de Transporte (CMTR). No caso do Rio de Janeiro, esse órgão foi criado apenas em 2013, na esteira dos movimentos de protestos de rua ocorridos em junho daquele ano ${ }^{12}$.

Do ponto de vista de Eduardo Paes, prefeito à época,

O conselho faz parte de um pacote de ações que anunciamos há dois meses, quando houve as manifestações, para melhorar o transporte público na cidade. Já implantamos também o site da transparência da mobilidade. Os conselheiros terão acesso e prioridade a todas as informações (ALBUQUERQUE, 04/09/2013).

No caso carioca, o conselho é composto por 24 integrantes ${ }^{13}$, entre membros da administração pública direta e de instituições da sociedade civil. Entre as entidades componentes, apenas a Associação de Defesa dos Usuários de Transportes no Estado do Rio de Janeiro (Adut) representa os usuários diretamente, fato que aponta para a fraca vocalização deles nas discussões sobre o tema no órgão criado para discutir o transporte.

O conselho não conta com site próprio. Segundo as informações no portal da SMTR, as reuniões entre conselheiros ocorreram uma vez em 2013 (na inauguração) e uma vez por mês entre outubro de 2018 e agosto de 2019. Isso demonstra a expressiva irregularidade de funcionamento do conselho e sua pouca efetividade de ação e de acompanhamento da dinâmica do serviço de transporte. 
Se pensarmos em outras entidades, tanto as com representação no CMTR como aquelas fora dele, encontramos um conjunto de ONGs e institutos de pesquisa universitários dedicados ao assunto. Cito como exemplos o Instituto de Políticas de Transporte e Desenvolvimento (ITDP), o Transporte Ativo e a Casa Fluminense. Essas organizações dedicam-se a temas concernentes à mobilidade urbana como um todo e têm se colocado no cenário carioca de forma mais visível na agenda pública do que no próprio conselho municipal e em outras instituições.

O ITDP se apresenta como entidade promotora do uso de transporte sustentável, concentrando esforços em reduzir as emissões de carbono e a desigualdade social ${ }^{14}$. Em relação ao transporte coletivo, a ênfase da entidade recai sobre metrô e BRT. A Transporte Ativo dedicase ao impulsionamento de modos de locomoção não motorizados, como a bicicleta ${ }^{15}$. Ambos são patrocinadas por empresas privadas e mantêm parcerias com os governos municipal e estadual do Rio de Janeiro. A Casa Fluminense, por sua vez, aparece como ator coletivo envolvido em discussões sobre temas também relacionados à mobilidade urbana. A entidade coloca-se como polo de uma rede de pessoas e organizações composta por pesquisadores acadêmicos, ativistas, cidadãos e consultores de variados temas concernentes ao modelamento da Região Metropolitana do Rio de Janeiro (RMRJ) ${ }^{16}$. Nenhuma das instituições citadas tem o objetivo de discutir exclusivamente o transporte coletivo convencional realizado por ônibus. As pautas de mobilidade acionadas concentram-se em modelos alternativos denominados sustentáveis, como a bicicleta, ou em modais menos poluentes, como o metrô.

Argumento, então, que a mobilidade urbana pode ser entendida como campo agregador de temas amplos referentes aos modos como nos deslocamos, principalmente em cidades médias e grandes. O tema reúne o planejamento de vias de trânsito e o transporte. Entidades dedicadas ao assunto e o governo estadual têm discutido os modais não apenas do Rio de Janeiro, mas também de sua região metropolitana.

Trens, metrô, BRT, veículo leve sobre trilhos (VLT), ônibus convencionais e barcas compõem o amplo sistema de transporte de massa da RMRJ. Um morador de Nova Iguaçu (Baixada Fluminense) que trabalhe na Barra da Tijuca (Zona Oeste carioca), por exemplo, poderá utilizar os trens da Supervia até a estação Central do Brasil (Centro). De lá, terá as opções de embarcar nas linhas 1 ou 4 do Metrô Rio até o Jardim Oceânico (Barra da Tijuca) e, a partir dali, tomar um ônibus comum ou o BRT até seu destino final. O exemplo é apenas uma ilustração para demonstrar as conexões entre o transporte municipal carioca e aqueles presentes na Baixada Fluminense.

Pesquisadores do Instituto Alberto Luiz Coimbra de Pós-Graduação e Pesquisa de Engenharia (Coppe) da Universidade Federal do Rio de Janeiro (UFRJ) e de outros centros de pesquisa, como o Instituto de Pesquisa e Planejamento Urbano e Regional (Ippur), também da UFRJ, têm desenvolvido trabalhos no campo da mobilidade urbana. ONGs como as citadas anteriormente, 
centradas no desenvolvimento sustentável do Rio e da RMRJ, também afirmam se dedicar ao desafio de planejar a metrópole, tornando-a mais sustentável. Grandes projetos elaborados localmente, como o Modelar a Metrópole ${ }^{17}$, financiados por organismos internacionais como o Banco Interamericano de Desenvolvimento (BID), conferem destaque ao tema.

A mobilidade urbana, então, constrói-se como categoria ao mesmo tempo de análise acadêmica e de intervenção, por parte de associações estatais e não estatais, nos espaços públicos das cidades. Ela conta com uma política nacional específica, organizada por meio da lei federal no 12.587, de janeiro de 2012, que a define como "condição em que se realizam os deslocamentos de pessoas e cargas no espaço urbano" (BRASIL, 2012). A mesma lei estabelece o transporte coletivo, situado nesse grande campo da mobilidade urbana, como "serviço público de transporte de passageiros acessível a toda a população mediante pagamento individualizado, com itinerários e preços fixados pelo poder público" (Ibid.).

O transporte público, entretanto, apresenta nuances e discussões distintas conforme o modal. Por isso, as problematizações a seu respeito ocorrem de maneira fragmentada, canalizadas para as demandas específicas de cada caso, como a implementação de refrigeração na frota dos ônibus convencionais, o aumento do preço da tarifa ou as condições precárias das estações do BRT e a degradação do asfalto dos corredores expressos.

Assim, percebe-se que as estratégias de ação do associativismo formal estão mais próximas dos questionamentos referentes ao tema da mobilidade urbana e menos do transporte coletivo de modo específico. No primeiro caso, constata-se a atuação de uma rede de ONGs e outras entidades não estatais empenhadas em relacionar os vários aspectos do planejamento e do desenvolvimento das metrópoles com os modos pelos quais os citadinos circulam nesse espaço. Contribuem, assim, para fomentar debates sobre o grande problema dos deslocamentos urbanos, mantendo-o na agenda pública das grandes cidades. Os públicos componentes das instituições articulam modos de definição dos problemas e apresentam propostas de melhoria ao poder público ${ }^{18}$. Eventos são organizados com o intuito de agregar diferentes atores interessados na questão, como parceiros da iniciativa privada, coletivos e demais movimentos sociais ligados a pautas urbanas e de desenvolvimento sustentável das metrópoles. De outro lado, o transporte coletivo operado por ônibus convencionais e BRT é discutido ora em momentos específicos, ora como grande síntese de deficiências e insatisfações por parte da população, que critica mazelas na oferta do serviço, ou da imprensa local.

Observei, na pesquisa, a ação de uma modalidade não associativa de ação coletiva. $\mathrm{O}$ movimento de associações estruturadas está mais próximo de uma problematização (mais especializada) da mobilidade urbana, tema guarda-chuva caracterizado por abarcar diversas dimensões da circulação de massa. Nesse sentido, a opinião pública, ou seja, o juízo elaborado e difundido pelos indivíduos e compartilhado coletivamente (TARDE, 2005[1901]), se caracteriza 
como dimensão de maior recorrência entre os atores do transporte carioca, e a circulação da crítica se torna, ela mesma, a arenização do problema.

Jornais e páginas de redes sociais como Facebook podem ser pensados como instâncias em que a propagação de qualificações do transporte põe em contato as opiniões dos usuários, conformando a convergência de um conjunto de julgamentos sobre uma realidade problemática. Embora a pesquisa não tenha explorado etnograficamente como as críticas circulam na dinâmica situada do transporte, qualquer pessoa com o mínimo de contato com esse serviço público percebe que, no nível da vida cotidiana, os diálogos corriqueiros em pontos de embarque e desembarque, terminais e estações definem tipos de conversação tão responsáveis em fazer a crítica circular entre o público de passageiros quanto a opinião pública - embora esta também esteja presente nessa dimensão ordinária da vida cotidiana.

Assim, a arenização do transporte coletivo carioca, ocorrida por meio da crítica dispersa, aponta para a atuação de um posicionamento de desejo de mudanças originado de uma extrema insatisfação. Os problemas dos públicos (DEWEY, 2008[1927]), dessa maneira, são experimentados cotidianamente e definidos (no sentido pragmático) de maneira abstrata (TARDE, 2005[1901]) entre componentes de um ajuntamento difuso formado a distância. O problema que não se resolve torna-se uma representação social geral dos usuários sobre as possibilidades e impossibilidades de resolução da problemática do transporte.

Não ignoro a manifestação de grupos coletivos reivindicadores de melhorias. Eles estão presentes principalmente por meio de associações de bairro. Contudo, essas iniciativas pouco apareceram no material empírico. Além disso, quando presentes, não obtiveram força para agregar e manter arenas de publicização em torno de questões pautadas por eles como problemáticas. Parece haver dificuldades nesse tipo de iniciativa em captar a atenção pública. De todo modo, a pesquisa não teve a intenção de aprofundar esse debate, e sim de apontar uma forma alternativa para pensar a materialização de mobilizações coletivas e de formas de contestação contra a precariedade de prestação de um serviço. Uma nova investigação, concentrada em mapear os modos de ação desse tipo, partindo principalmente de associações de bairro e demais tipos de representação de pautas locais, poderia fornecer elementos para se refletir sobre o modo como os problemas do transporte são tematizados por elas, em uma perspectiva situada.

\section{Considerações finais}

O abafamento da problematização das críticas ao transporte coletivo do Rio de Janeiro em arenas públicas formais por parte dos usuários desse serviçoaponta para um processo de 
publicização caracterizado pelo contato do discurso crítico produzido pelos envolvidos de maneira intangível (CHATEAURAYNAUD, 2004) e banal. Assim, contribui para uma aparente perda de força na capacidade de alteração do mundo, justamente por ser repetitivo, recorrente e direcionado a um grande fenômeno de transtornos. Nesses termos, a crítica formulada dessa maneira contribui para a formação de uma espécie de mosaico em que cada uma das peças é composta por problemas específicos do transporte. Quando olhamos a certa distância, enxergamos um único desenho, eclipsando suas partes constitutivas, vistas como síntese no desenho final. De modo ambíguo, a veiculação da crítica de forma dispersa produz ela mesma uma capacidade de problematização (arenização) do tema, impactando sobremaneira o entendimento da experiência no contexto do objeto analisado.

De tudo visto até aqui, posso afirmar que a ideia do grande problema que não se resolve configura uma espécie de buraco negro da ação coletiva (mesmo que em determinados momentos ofereça a possibilidade de escape). Os críticos agem na dinâmica do transporte, concebendo-a como desfavorável e aparentemente imutável.

Essa constatação encontra paralelo com outras áreas da vida social, como a saúde, a educação e a segurança pública. Todos elas constituem serviços públicos (portanto, de responsabilidade estatal). A oferta deles assenta-se em um arcabouço jurídico e normativo referente ao dever do Estado em os prover e relativo a parâmetros de qualidade a serem seguidos para sua organização e manutenção. No entanto, em termos práticos, há uma desarticulação entre a norma (ideal) e a prática (deficiente, aos olhos dos críticos). As representações sobre um serviço público mal prestado, ou um grande problema que não se resolve, extrapolam, assim, o campo dos transportes, sendo constitutivas também de outras realidades.

Busquei apresentar neste artigo uma proposta de operacionalização do modelo de problemas e arenas públicas ajustado à realidade do material empírico analisado na pesquisa. O desenho de associativismo americano mobilizado por Dewey (2008[1927]) e Gusfield (1963, 1981) apresenta nuances em relação ao encontrado no contexto brasileiro. Neste, a própria definição de problema público torna-se fluida, na medida em que, no caso do transporte carioca, a publicização de insatisfações pode ocorrer de maneira não associativa, contribuindo para a fragilidade na formação de públicos aos moldes do modelo deweyano. Essa constatação nos permite deslocar a discussão teórica sobre públicos, construindo diálogos com o pensamento de Tarde (2005[1901]) sobre o tema. Assim, temos a possibilidade de pensarmos tal noção em termos não associativos, a partir da ideia de públicos dispersos, formados a distância e postos em contato abstratamente.

Por fim, é importante observar que, tomando a fórmula do problema público composta por publicização, engajamento de atores (em número significativo) e solução, percebemos que esta última etapa pode não ocorrer em todos os casos. Não há um regramento capaz de determinar 
que um problema reconhecido por muitos como de importância coletiva será, necessariamente, resolvido ou sequer enfrentado. Os transtornos podem estar fortemente rotinizados e, portanto, tratados pelas pessoas de maneira ritualística. Os usuários criticam, apontam a absurdidade da persistência dos mesmos problemas e cobram do poder público medidas. Em contrapartida, este último pressiona as empresas concessionárias e afirma estar fazendo todo o possível para sanar os transtornos. As empresas, por fim, anunciam medidas de contenção das queixas. Na prática, a percepção dos reclamantes é a de que pouca coisa foi alterada, justamente porque suas queixas se repetem ao longo do tempo. Essa dinâmica marca de maneira profunda a experiência urbana do transporte coletivo do Rio de Janeiro.

\section{Notas}

1 Este artigo apresenta parte das discussões e resultados de minha pesquisa de mestrado, orientada pelo professor Alexandre Werneck, a quem agradeço imensamente pelas contribuições.

${ }^{2}$ As falas de usuários citadas neste artigo foram em sua maioria retiradas desse periódico. O jornal não oferece informações detalhadas sobre os responsáveis pelas falas, nem sobre o modo pelo qual o texto foi endereçado a sua redação, se por cartas ou via e-mail. Entretanto, a fim de orientar a observação da amostra, apresento, sempre que possível, o nome, idade, profissão e local de moradia dos leitores. As transcrições das falas são textuais e manterão as grafias, regências e concordâncias originais.

${ }^{3}$ Nesse movimento, coloco entre parênteses o caráter do próprio jornal como actante relevante na discussão, a fim de, tirando partido de sua lógica operacional fundada justamente na crítica, tratá-lo heuristicamente apenas como suporte das falas aqui analisadas. Segundo Werneck (2004), o jornal, como ator moral, tem seu moralismo como fundamento técnico da sua própria atividade formal: toda matéria jornalística se fundamenta em uma dinâmica de apontamento de um fato relevante e um questionamento das responsabilidades pelo mesmo, buscando apontar responsáveis e por vezes culpados. Nesse sentido, ele pode ser entendido como um empreendedor moral ou como mantenedor de regras, ambos no sentido de Howard Becker (2008), isto é, como um agente mobilizador de posturas críticas e de verificação da realidade. Usuários procuram o jornal para formular denúncias porque acreditam na divulgação de suas demandas e na força moral de tal canal de amplificação - apresentado como "quarto poder", fiscalizador dos demais. Buscam ainda iniciar um processo de "correção" do comportamento de homens públicos e atingir a atenção dos destinatários, tanto de leitores, como os próprios alvos das contestações. O encadeamento de atores, os fatos selecionados e as estratégias utilizadas pelo jornal para publicizar os acontecimentos estão contidos em duas lógicas: a primeira delas refere-se às preferências políticas e ideológicas dos periódicos (em geral, diluídas em sua "correção política"); a segunda concentra-se nos aspectos referentes ao etos profissional e uma esfera mais formal do funcionamento de um jornal. As análises desta pesquisa estarão circunscritas à segunda lógica.

${ }^{4}$ A pesquisa também se voltou para outros materiais empíricos: os dados oficiais e estatísticos da Secretaria Municipal de Transportes (SMTR) referentes às reclamações e denúncias da população; publicações e comentários de internautas em páginas de Facebook destinadas ao tema. Explorar todo esse universo ultrapassaria os limites deste artigo, de modo que me concentro apenas nos elementos extraídos do jornal.

${ }^{5}$ A descrição marca posição do próprio jornal, ao apresentar o ponto de vista dos repórteres que percorreram os terminais do BRT TransOeste entre os trechos de Santa Cruz e Barra, na Zona Oeste do Rio de Janeiro.

${ }^{6}$ Mais detalhes sobre o modal ferroviário atuante na cidade do Rio de Janeiro e na Região Metropolitana do Rio de Janeiro (RMRJ), bem como os usos e apropriações feitos dele por parte dos passageiros, podem ser observados em Pires (2011).

7 Utilizo o termo a partir do entendimento do próprio Tarde (2005[1901]), sintetizado por ele como o conjunto de todos os juízos: "a opinião, diremos, é um grupo momentâneo e mais ou menos lógico de juízos, os quais, respondendo a problemas atualmente colocados, acham-se reproduzidos em numerosos exemplares em pessoas do mesmo país, da mesma época, da mesma sociedade" (p. 63). Em outra passagem, ele afirma: "a opinião está para o público, nos tempos modernos, assim como a alma está para o corpo" (lbid., p. 61). A opinião seria então uma espécie de metafísica fundamentadora das racionalidades. Ela é construída socialmente e configuraria uma ideia não inventada pelos indivíduos, mas trazida à tona coletivamente. 
${ }^{8}$ Definida por Tarde (2005[1901], p. 76) como "todo diálogo sem utilidade direta e imediata, em que se fala sobretudo por falar", é o fluxo de pensamento que molda a opinião. Além disso, ela é o cerne da atenção espontânea, tornando coletivas as ideias.

${ }^{9}$ O posicionamento assemelha-se à ideia de Thomas e Thomas (1938[1928]) a respeito da definição de situação.

${ }^{10}$ Composta em maio de 2020 pelos vereadores Alexandre Isquierdo (Democratas), Major Elitusalem (PSC) e Luiz Carlos Ramos Filho (PMN). Segundo informações presentes no site da Câmara de Vereadores, tem o objetivo de "estudar, debater e pesquisar questões relacionadas aos sistemas viário, de circulação e de transportes" (Disponível [on-line] em: http://www.camara.rio/atividade-parlamentar/comissoes/permanentes/transportes-e-transito). É relevante salientar também a ocorrência de duas Comissões Parlamentares de Inquérito (CPIs) dos ônibus nesta casa legislativa: a primeira, em 2013, ocorrida após as manifestações de junho daquele ano, e a segunda realizada na esteira do escândalo de corrupção envolvendo gestores públicos municipais e donos de empresas de ônibus, no âmbito da operação Lava Jato da Polícia Federal.

${ }^{11}$ Neste artigo, cito o referido evento por ter sido o mais expressivo no campo dos transportes na última década e por ser um exemplo de arena pública associativa clássica. No contexto do Rio de Janeiro, poderia elencar outras miniarenas iniciadas por meio de "gatilhos", acontecimentos propulsores de uma intensa discussão sobre o fenômeno: a questão do valor "justo" da tarifa, a refrigeração total da frota, os acidentes envolvendo os ônibus — pondo em evidência a fiscalização da Prefeitura quanto às condições de segurança em que esses veículos operam —, os escândalos de corrupção no setor, entre outros assuntos.

${ }^{12}$ Órgão criado por meio do decreto no 37.301, de 25 de junho de 2013 (RIO DE JANEIRO, 2013), pelo prefeito Paes, e alterado pelo decreto no 46.377, de agosto de 2019 (Idem, 2019), na gestão de Crivella. Originalmente, o Conselho exercia a função de representação paritária e deliberativa; com a alteração, passou a ser consultivo. Além disso, sua presidência foi transferida do prefeito para o secretário municipal de Transportes.

${ }^{13}$ Do poder público, representantes das secretarias municipais de Transporte, Urbanismo, Conservação, Ordem pública; Subsecretarias de Pessoa com Deficiência, e de Políticas para o Idoso; Guarda Municipal; Companhia de Engenharia de Tráfego do Rio de Janeiro (CET-Rio); Secretaria Estadual de Transportes; Departamento de Trânsito do Estado do Rio de Janeiro (Detran-RJ); Companhia Docas do Rio de Janeiro; Banco Nacional de Desenvolvimento Econômico e Social (BNDES); Companhia de Desenvolvimento Urbano da Região do Porto do Rio de Janeiro (CDURP). Da sociedade civil, representantes do Conselho Regional de Engenharia e Agronomia (Crea); Conselho de Arquitetura e Urbanismo do Rio de Janeiro (CAU-RJ); Linha Amarela (Lamsa); Concessionária do VLT Carioca; Associação Nacional de Transportes Públicos (ANTP); Supervia Trens Urbanos; Rio Ônibus - Sindicato das Empresas de ônibus da Cidade do Rio de Janeiro; Fórum Permanente de Mobilidade Urbana (FMU); Metrô Rio; Associação de Defesa dos Usuários de Transportes no Estado do Rio de Janeiro (ADUT); ONGs Transporte Ativo e Instituto de Políticas de Transporte e Desenvolvimento (ITDP). Essa composição está contida na resolução "P" 127/SMTR de setembro de 2019. Ela alterou significativamente a composição da sociedade civil no conselho, retirando o assento de universidades, por exemplo. Disponível (on-line) em: https://doweb.rio.rj.gov.br/portal/visualizacoes/pdf/4281\#/p:104/e:4281?find=resolu\%C3\%A7\%C3\%A30\%20127

${ }^{14} \operatorname{Ver}$ (on-line): http://itdpbrasil.org.br

${ }^{15}$ Ver (on-line): http://transporteativo.org.br/ta

${ }^{16}$ Ver (on-line): http://casafluminense.org.br/a-casa

${ }^{17} \mathrm{O}$ projeto, instituído pelo decreto estadual no 44.905 , de 11 de agosto de 2014, tem o objetivo de coordenar os interesses comuns dos 21 municípios componentes da RMRJ.

${ }^{18}$ Grande número de documentos, relatórios e proposta de intervenção podem ser encontrados nos sites das associações citadas. 


\section{Referências}

BECKER, Howard. Social Problems: A Modern Approach. Nova York: John Wiley, 1966.

BECKER, Howard. Outsiders: Estudos de sociologia do desvio. Rio de Janeiro: Zahar, 2008[1963].

BLUMER, Herbert. "Social Problems as Collective Behavior". Social Problems, vol. 18, n. 3, pp. 298-306, 1971.

BRASIL. Lei federal n 13.010, de junho de 2014: Altera a Lei no 8.069, de 13 de julho de 1990 (Estatuto da Criança e do Adolescente), para estabelecer o direito da criança e do adolescente de serem educados e cuidados sem o uso de castigos físicos ou de tratamento cruel ou degradante, e altera a Lei no 9.394, de 20 de dezembro de 1996. Brasília: Presidência da República, 2014. Disponível em: http://www.planalto.gov.br/ccivil_03/_ato2011-2014/2014/lei/113010.htm

BRASIL. Lei $\mathrm{n}^{\circ}$ 12.587, de 3 de janeiro de 2012: Institui as diretrizes da Política Nacional de Mobilidade Urbana; revoga dispositivos dos Decretos-Leis no ${ }^{\circ}$ 3.326, de 3 de junho de 1941, e 5.405, de 13 de abril de 1943, da Consolidação das Leis do Trabalho (CLT), aprovada pelo DecretoLei $\mathrm{n}^{\circ}$ 5.452, de $1^{\circ}$ de maio de 1943, e das Leis $\mathrm{n}^{\circ} \mathrm{s}$ 5.917, de 10 de setembro de 1973, e 6.261, de 14 de novembro de 1975; e dá outras providências. Brasília: Presidência da República, 2012. Disponível em: https://www.planalto.gov.br/ccivil_03/_ato2011-2014/2012/lei/112587.htm

BOLTANSKI, Luc. El amor y la justicia como competências: Tres ensayos de sociología de la acción. Buenos Aires: Amorrortu, 2000[1990].

BOLTANSKI, Luc. Distant Suffering: Morality, Media and Politics. Nova York: Cambridge University Press, 2004[1993].

BOLTANSKI, Luc; THÉVENOT, Laurent. "A Sociologia da capacidade crítica”. Antropolítica, vol. 23, n. 2, pp. 121-144, 2007[1999].

BOLTANSKI, Luc; THÉVENOT, Laurent. A justificação: Sobre as economias da grandeza. Rio de Janeiro: Editora UFRJ, 2020[1991].

CATTANI, Antonio David (org). \#protestos: Análises das ciências sociais. Porto Alegre: Tomo, 2014.

CEFAÏ, Daniel. "La construction des problèmes publics: Définitions de situations dans des arènes publiques”. Réseaux, vol. 14, n. 75, pp. 43-66, 1996.

CEFAï, Daniel. "Como uma associação nasce para o público: Vínculos locais e arena pública em torno da associação La Bellevilleuse em Paris”. In: CEFAÏ, Daniel; MELLO, Marco Antônio; MOTA, Fábio; VEIGA, Felipe. Arenas públicas: Uma etnografia da vida associativa. Niterói: Eduff, 2011, pp. 67-102.

CEFAï, Daniel. “¿Qué es una arena pública? Algunas pautas para un acercamiento pragmático”. In: CEFAI, Daniel; JOSEPH, Isaac (orgs). La herencia del pragmatismo: Conflictos de urbanidad y pruebas de civismo. La Tour d'Aigues: Editions de l'Aube, 2012[2002], pp. 51-81.

CEFAÏ, Daniel. "Investigar los problemas públicos: Com y más allá de Joseph Gusfield". In: GUSFIELD, Joseph. La cultura de los problemas públicos: El mito del conductor alcoholizado versus la sociedad inocente. Buenos Aires: Siglo XXI, 2014, pp. 11-58. 
CLAVERIE, Élisabeth. "La naissance d'une forme politique: L'affaire du Chevalier de La Barre". In: ROUSSIN, Philippe (org). Critique et affaires de blasphème à l'époque des Lumières. Paris: Honoré Champion, 1998, pp. 185-260.

CHATEAURAYNAUD, Francis. "L'épreuve du tangible: Expériences de l'enquête et surgissements de la preuve”. Raisons Pratiques, vol. 15, pp. 167-194, 2004.

DEWEY, John. "Em busca do público". In: FRANCO, Augusto; POGREBINSCHI, Thammy (orgs). Democracia cooperativa: Escritos políticos escolhidos de John Dewey. Porto Alegre: EdiPUCRS, 2008[1927], pp. 12-34.

FREIRE, Jussara. Problemas públicos e mobilizações coletivas em Nova Iguaçu. Rio de Janeiro: Garamond, 2016.

FULLER, Richard; MYERS, Richard. "Some Aspects of a Theory of Social Problems". American Sociological Review, vol. 6, n. 1, pp. 24-32, 1941a.

FULLER, Richard; MYERS, Richard. "The Natural History of a Social Problem". American Sociological Review, vol. 6, n. 3, pp. 320-328, 1941 b.

GARFINKEL, Harold. "O que é etnometodologia". In: GARFINKEL, Harold. Estudos de etnometodologia. Petrópolis: Vozes, 2018[1967], pp. 93-121.

GOFFMAN, Erving. Os quadros da experiência social: Uma perspectiva de análise. Petrópolis: Vozes, 2012[1974].

GOFFMAN, Erving. A representação do eu na vida cotidiana. Petrópolis: Vozes, 2014[1959].

GUALANDE JUNIOR. Ailton. Mosaico de críticas: Formação e dispersão de públicos em torno do transporte coletivo carioca. Dissertação (Mestrado em Sociologia [com concentração em Antropologia]) - Universidade Federal do Rio de Janeiro, Rio de Janeiro, 2019.

GUSFIELD, Joseph. Symbolic Crusade: Status Politics and the American Temperance Movement. Urbana: University of Illinois Press, 1963.

GUSFIELD, Joseph. The Culture of Public Problems: Drinking-Driving and the Symbolic Order. Chicago: University of Chicago Press, 1981.

LOURENÇO, Alice. Quem tem direito à cidade? Lutas pelo direito de ir e vir na metrópole do Rio de Janeiro (1980-2005). Dissertação (Mestrado em Planejamento Urbano e Regional) Universidade Federal do Rio de Janeiro, Rio de Janeiro, 2006.

MAMANI, Hernán. Transporte informal e vida metropolitana: Um estudo do Rio de Janeiro nos anos 90. Tese (Doutorado em Planejamento Urbano e Regional) - Universidade Federal do Rio de Janeiro, Rio de Janeiro, 2004.

MAMANI, Hernán; FREIRE, Jussara. "Cartografia do 'Movimento pelo Passe Livre' na imprensa do estado do Rio de Janeiro”. In: EGLER, Tamara Cohen (org). Reinvenção da democracia na América Latina. Rio de Janeiro: Letra Capital, 2013, pp. 207-212.

MEAD, George Herbert. Mind, Self, and Society. Chicago: University of Chicago Press, 1934.

MERTON, Robert; NISBET, Robert (orgs). Contemporary Social Problems. Nova York: Harcourt Brace and World, 1961. 
MOISÉS, José Álvaro; ALIER, Verena Martínez. “A revolta dos suburbanos ou 'Patrão, o trem atrasou”'. In: MOISES, José Álvaro; MARTINEZ-ALIER, Verena; OLIVEIRA, Francisco; SOUZA LIMA, Sérgio (orgs). Contradições urbanas e movimentos sociais. Rio de Janeiro: Paz e Terra, 1978, pp. 13-63.

PARK, Robert Ezra. La foule et le public. Lyon: Parangon/Vs, 2007[1975].

PIRES, Lenin. Esculhamba, mas não esculacha! Uma etnografia dos usos urbanos dos trens da Central do Brasil. Niterói: Eduff, 2011.

RICOEUR, Paul. Tempo e narrativa: A intriga e a narrativa histórica. São Paulo: Martins Fontes, 2010[1983].

RIO DE JANEIRO. Decreto no 37.301, de 25 de junho de 2013: Dispõe sobre a criação do Conselho Municipal de Transportes - CMTR, e dá outras providências. Rio de Janeiro: Diário Oficial do Município do Rio de Janeiro, 2013. Disponível em: https://doweb.rio.rj.gov.br/portal/visualizacoes/pdf/2106\#/p:4/e:2106?find=decreto\%2037.301

RIO DE JANEIRO. Decreto no 46.377, de 15 de agosto de 2019: Altera o decreto $\mathrm{n}^{\circ}$ 37.301, de 25 de junho de 2013, que dispõe sobre a criação do Conselho Municipal de Transportes - CMTR. Rio de Janeiro: Diário Oficial do Município do Rio de Janeiro, 2019. Disponível em: https://doweb.rio.rj.gov.br/portal/visualizacoes/pdf/4245\#/p:3/e:4245?find=decreto\%2046.377

RIO DE JANEIRO. Resolução "P” 127/SMTR, de 19 de setembro de 2019: Altera a composição do Conselho Municipal de Transportes - CMTR, e dá outras providências. Rio de Janeiro: Diário Oficial do Município do Rio de Janeiro, 2019. Disponível em: https://doweb.rio.rj.gov.br/portal/visualizacoes/pdf/4281\#/p:104/e:4281?find=resolu\%C3\%A 7\%C3\%A3o\%20127

STRAUSS, Anselm. Espelhos e máscaras. São Paulo: Edusp, 1999[1967].

STRAUSS, Anselm. Negotiations: Varieties, Processes, Contexts and Social Order. San Francisco: Jossey-Bass, 1978a.

STRAUSS, Anselm. "A Social World Perspective". In: DENZIN, Norman (org). Studies in Symbolic Interaction, vol. 1. Greenwich: Jai, 1978b, pp. 119-128.

SCHÜTZ, Alfred; LUCKMANN Thomas. The Structures of the Life-World. Evanston: Northwestern University Press, 1973.

VAINER, Carlos et al. Cidades rebeldes: Passe livre e as manifestações que tomaram as ruas do Brasil. São Paulo: Boitempo, 2013.

TARDE, Gabriel. A opinião e as massas. São Paulo: Martins Fontes, 2005[1901].

THÉVENOT, Laurent. "Les investissements de forme”. In: THÉVENOT, Laurent (org). Conventions économiques. Paris: PUF, 1986, pp. 21-71.

THOMAS William e THOMAS, Dorothy. The Child in America: Behavior Problems and Programs. Nova York: A.A. Knopf, 1938[1928].

WALLER, Willard. "Social Problems and the Mores". American Sociological Review, vol. 1, n. 6 , pp. 922-934, 1936. 
WERNECK, Alexandre. Comunicação e cinismo: A razão cínica na esfera pública observada na cobertura do Primeiro de Maio em jornais. Dissertação (Mestrado em Comunicação e Cultura) - Universidade Federal do Rio de Janeiro, Rio de Janeiro, 2004.

WERNECK, Alexandre; LORETTI, Pricila. "Critique-Form, Forms of Critique: The Different Dimensions of the Discourse of Discontent". Sociologia \& Antropologia, Rio de Janeiro, vol. 8, n. 3, pp. 973-1008, 2018.

Fontes da imprensa

ALBUQUeRQUe, Ricardo. "Prefeitura do Rio instala Conselho Municipal de Transporte". Rio Prefeitura, Notícia, 4 set. 2013. Disponível em: http://www.rio.rj.gov.br/web/guest/exibeconteudo?id=4359384

BRAGA, Bruno. "Usuários passam aperto no lotadão Transoeste". Extra, Rio de Janeiro, 22 mar. 2013, p. 4.

EXTRA. “Carta branca/comunidade”. Extra, Rio de Janeiro, 19 maio 2010, p. 2.

EXTRA. “Carta branca/comunidade”. Extra, Rio de Janeiro, 30 nov. 2011, p. 2.

EXTRA. "Carta branca/comunidade". Extra, Rio de Janeiro, 12 abr. 2014, p. 2.

EXTRA. “Carta branca/comunidade”. Extra, Rio de Janeiro, 10 jun. 2015, p. 2.

EXTRA. “Carta branca/comunidade”. Extra, Rio de Janeiro, 12 jun. 2017, p. 4.

OTAVIO, Chico et al. "Enquanto isso, quem sofre é o passageiro". Extra, Rio de Janeiro, 15 nov. 2017, p. 7.

RAMIRO, Daniele. "Para passageiros, o corredor para ônibus virou o 'BRTrem'”. Extra, Rio de Janeiro, 1 jul. 2012, p. 15.

RIBEIRO, Geraldo. “Insatisfação que não é passageira”. Extra, Rio de Janeiro, 25 jun. 2017, p. 5.

ROHDE, Bruno. "Pneus carecas, vidros trincados e goteiras: Passageiros em perigo". Extra, Rio de Janeiro, 6 fev. 2009, p. 3.

\begin{abstract}
AILTON GUALANDE JUNIOR (jrgualande@hotmail.com) é doutorando do Programa de Pós-Graduação em Sociologia e Antropologia (PPGSA) da Universidade Federal do Rio de Janeiro (UFRJ, Brasil), mestre pelo mesmo programa e licenciado e bacharel em ciências sociais pela Universidade Federal Fluminense (UFF, Campos dos Goytacazes, Brasil). É pesquisador do Núcleo de Estudos da Cidadania, Conflito e Violência Urbana (Necvu) da UFRJ.
\end{abstract}

